\title{
Beauveria bassiana Lipase A expressed in Komagataella (Pichia) pastoris with potential for biodiesel catalysis
}

OPEN ACCESS

Edited by:

Vijai Kumar Gupta,

National University of Ireland, Galway,

Ireland

Reviewed by:

Jiangxin Wang,

Shenzhen University, China

Lucilla lacumin,

University of Udine, Italy

${ }^{*}$ Correspondence:

Maria L. T. M. Polizeli,

Departamento de Biologia, Faculdade de Filosofia Ciências e Letras de Ribeirão Preto, Universidade de São Paulo, Avenida Bandeirantes 3900, Ribeirão Preto, São Paulo

14040-901, Brazil polizeli@ffclrp.usp.br

Specialty section

This article was submitted to Microbiotechnology, Ecotoxicology

and Bioremediation,

a section of the journal

Frontiers in Microbiology

Received: 11 August 2015 Accepted: 22 September 2015

Published: 07 October 2015

Citation:

Vici AC, da Cruz AF, Facchini FDA

de Carvalho CC, Pereira MG

Fonseca-Maldonado $R$, Ward RJ,

Pessela BC, Fernandez-Lorente $G$

Torres FAG, Jorge JA

and Polizeli MLTM (2015) Beauveria

bassiana Lipase $A$ expressed

in Komagataella (Pichia) pastoris with

potential for biodiesel catalysis.

Front. Microbiol. 6:1083.

doi: 10.3389/fmicb.2015.01083

\author{
Ana C. Vici', Andrezza F. da Cruz', Fernanda D. A. Facchini', Caio C. de Carvalho', \\ Marita G. Pereira², Raquel Fonseca-Maldonado ${ }^{3}$, Richard J. Ward ${ }^{3}$, \\ Benevides C. Pessela ${ }^{4}$, Gloria Fernandez-Lorente ${ }^{4}$, Fernando A. G. Torres ${ }^{5}$, \\ João A. Jorge ${ }^{2}$ and Maria L. T. M. Polizeli ${ }^{2 *}$
}

${ }^{1}$ Departamento de Bioquímica e Imunologia, Faculdade de Medicina de Ribeirão Preto, Universidade de São Paulo, Ribeirão Preto, Brazil, ${ }^{2}$ Departamento de Biologia, Faculdade de Filosofia Ciências e Letras de Ribeirão Preto, Universidade de São Paulo, Ribeirão Preto, Brazil, ${ }^{3}$ Departamento de Química, Faculdade de Medicina de Ribeirão Preto, Universidade de São Paulo, Ribeirão Preto, Brazil, ${ }^{4}$ Departamento de Biotecnología y Microbiología de Alimentos, Instituto de Investigación en Ciencias de los Alimentos, Consejo Superior de Investigaciones Cientificas, Madrid, España, ${ }^{5}$ Departamento de Biologia Celular, Instituto de Ciências Biológicas, Universidade de Brasilia, Brasília, Brazil

Lipases (EC 3.1.1.3) comprise a biotechnologically important group of enzymes because they are able to catalyze both hydrolysis and synthesis reactions, depending on the amount of water in the system. One of the most interesting applications of lipase is in the biofuel industry for biodiesel production by oil and ethanol (or methanol) transesterification. Entomopathogenic fungi, which are potential source of lipases, are still poorly explored in biotechnological processes. The present work reports the heterologous expression and biochemical characterization of a novel Beauveria bassiana lipase with potential for biodiesel production. The His-tagged B. bassiana lipase $\mathrm{A}(\mathrm{Bb}\llcorner\mathrm{A})$ was produced in Komagataella pastoris in buffered methanol medium $(\mathrm{BMM})$ induced with $1 \%$ methanol at $30^{\circ} \mathrm{C}$. Purified BbLA was activated with $0.05 \%$ Triton X-100 and presented optimum activity at $\mathrm{pH} 6.0$ and $50^{\circ} \mathrm{C} . \mathrm{N}$-glycosylation of the recombinant BbLA accounts for $31.5 \%$ of its molecular weight. Circular dichroism and molecular modeling confirmed a structure composed of $\alpha$-helix and $\beta$-sheet, similar to $\alpha / \beta$ hydrolases. Immobilized BbLA was able to promote transesterification reactions in fish oil, demonstrating potential for biodiesel production. BbLA was successfully produced in $K$. pastoris and shows potential use for biodiesel production by the ethanolysis reaction.

\section{Keywords: lipase, Beauveria bassiana, heterologous expression, lipase purification, ethanolysis, biodiesel}

Abbreviations: BbLA, Beauveria bassiana Lipase A expressed in Komagataella pastoris; BMM, buffered methanol medium; bp, basis pair; BMMY, buffered methanol medium plus yeast; C18-Sep, Octadecyl-Sepabeads; CALB, C. antarctica lipase B; CCRD, central composite rotational design; $\mathrm{CTAB}$, cetyl trimethylammonium bromide; $\mathrm{D} / \mathrm{d}$, diameter of the halo/diameter of colony; DEPC, diethylpyrocarbonate; DHA, docosahexanoic acid; EPA, eicosapentaenoic acid; EstA, Aspergillus niger esterase A; Far-UV CD, far ultraviolet Circular Dichroism; GCLI, Geotrichum candidum lipase I; GCLII, Geotrichum candidum lipase II; GS115, strain of $K$. pastoris used in this work; IMAC- $\mathrm{Cu}^{2+}$, immobilized metal $\left(\mathrm{Cu}^{2+}\right)$ affinity chromatography; $\mathrm{k}_{\text {cat }}$, Turnover number; $\mathrm{K}_{\mathrm{M}}$, Michaelis constant; $\mathrm{MM}$, minimal medium; PDB, protein data base; $p I$, isoelectric point; $p N$, $p$-nitrophenol; $p \mathrm{NPB}, p$-nitrophenyl butirate; pPIC9k_CT, vector used in this work; RCLs, $R$. chinensis lipases; RML, R. miehei lipase; RT-PCR, real time PCR; SDS, sodium dodecyl sulfate; SDS-PAGE, sodium dodecyl sulfate-polyacrylamide gel electrophoresis; TLL, T. lanuginosa lipase; $\mathrm{V}_{\max }$, maximum reaction rate; YNB, yeast nitrogen base; YPM, yeast peptone medium. 


\section{Background}

Microbial lipases (EC 3.1.1.3) constitute a biotechnological important enzyme group because of their versatile properties and the relative ease of large-scale production compared to animal and vegetable homologues (Singh and Mukhopadhyay, 2012). Lipases belong to the carboxyl ester hydrolase family, which present activity against carboxylic ester bonds of triacylglycerols and act on the organic-aqueous interface releasing fatty acids and glycerol (Jaeger and Reetz, 1998; Bancerz and Ginalska, 2007; Lotti and Alberghina, 2007). These enzymes are able to catalyze both hydrolysis and synthesis reactions of esterification, transesterification, and interesterification, depending on the amount of water in the system (Krishna and Karanth, 2001; Gotor, 2002; Hasan et al., 2009). The different catalytic properties are very important for lipase applications, especially in the food, detergents, fine chemical synthesis, pharmaceutical, cosmetics, and biodiesel industries (Wang et al., 2002; Hasan et al., 2006; Freire and Castilho, 2008). There is therefore a strong interest in the investigation of new sources of lipases or in the enhancement of the production of existing sources.

Research on lipase applications is currently focused on the area of biofuels, since production of biodiesel is a promising substitute for diesel oil. Biodiesel can be produced from renewable resources such as vegetable oils, animal oil, and residual oil from industrial and domestic kitchens. In order to this application, lipases in aqueous-restricted environments and the presence of ethanol or methanol results in a transesterification reaction called alcoholysis, giving rise to fatty acid esters (Iso et al., 2001; Matsumoto et al., 2001; Parawira, 2009).

The use of lipases in biodiesel production is advantageous as compared to alkaline chemical catalysis, because the enzymatic route does not result in saponification reactions and the glycerin and biodiesel recovery is simpler with higher purity. In addition, the catalyst recovery is easy when the lipase is immobilized on inert supports, the energy cost is lower since lipases generally operate under mild temperature conditions, and as a consequence the environmental impact is significantly reduced (Yang et al., 2009; Bisen et al., 2010; Cavalcanti-Oliveira et al., 2011; Batista et al., 2013). However, alcoholysis using lipase is more expensive because of the high cost of the biological catalyst and the lower overall productivity as compared to the alkaline catalysis (Wang et al., 1988; Batista et al., 2013). The current studies on enzyme use are focused on increasing production, reducing costs and making lipases more efficient in transesterification reactions. These goals drive the search for new sources of lipases, as well as their overexpression, immobilization on different supports and modification of known enzymes.

The application of entomopathogenic fungi is mainly in the context of crop pest biocontrol, especially in organic farming. There are only a few reports in the biotechnology area, such as lipase production by Metarhizium anisopliae (Silva et al., 2005), Isaria fumosorosea (Ali et al., 2009, 2014) and by Beauveria bassiana (Mustafa and Kaur, 2010). In these molds, lipases play an important role during the infection of insects, hydrolyzing ester bonds in the lipoproteins, fats and waxes that are abundant in the insect exoskeleton (Ali et al., 2014). Hence, the study of entomopathogenic fungi as a source of lipases for application in catalysis may yield novel enzymes with improved features over existing industrial enzymes.

The genome of $B$. bassiana has been partially sequenced in mid-2012 (Xiao et al., 2012), and several genes encoding proteins with putative lipase function have been annotated, suggesting that this organism might be a promising source of this enzyme. This study reports the cloning and expression of one of these putative lipase genes in Komagataella pastoris and evaluation of the potential of the heterologous lipase for biodiesel production.

\section{Materials and Methods}

\section{Fungi Strain, Culture Medium, Total RNA Extraction and cDNA Preparation}

Beauveria bassiana CFF74 was grown in Khanna medium (Khanna et al., 1995) supplemented with $1 \%$ canola oil and $0.1 \%$ peptone at $30^{\circ} \mathrm{C}, 100 \mathrm{rpm}$ for $60 \mathrm{~h}$. Mycelia were harvested and frozen in liquid nitrogen. Total RNA was extracted by the TRIzol $^{\oplus}$ (Life technologiesTM) methodology. For this purpose, $1.0 \mathrm{~mL}$ of Trizol was used for each 50-100 mg of mycelium. Tubes were homogenized until mycelium was completely dissolved and then, incubated for $5 \mathrm{~min}$ at room temperature. Samples were quickly homogenized after the addition of $200 \mu \mathrm{L}$ of chloroform per $1 \mathrm{~mL}$ of Trizol used. Subsequently, samples were incubated at room temperature for $10 \mathrm{~min}$ and centrifuged at $12,000 \mathrm{~g}, 4^{\circ} \mathrm{C}$ for $15 \mathrm{~min}$. The aqueous phase was transferred to another clean tube. A volume of $500 \mu \mathrm{L}$ of isopropanol was added to the samples. After $3 \mathrm{~h}$ at room temperature, samples were centrifuged again at $12,000 \mathrm{~g}, 15 \mathrm{~min}, 4^{\circ} \mathrm{C}$ and the pellet was washed with $75 \%$ ethanol. Samples were homogenized in vortex and centrifuged at 7,000 $\mathrm{g}, 5 \mathrm{~min}, 4^{\circ} \mathrm{C}$. The supernatant was discarded. After drying for $30 \mathrm{~min}$ at room temperature, the pellets were resuspended in $100 \mathrm{~mL}$ DEPC-water and incubated for $10 \mathrm{~min}$ at $55^{\circ} \mathrm{C}$. Total RNA was quantified in NanoDrop spectrophotometer (Thermo Scientific) and analyzed in $1.5 \%$ agarose gel, in $1 \mathrm{x}$ TAE buffer at $80 \mathrm{~V}$ for $2 \mathrm{~h}$. After checking the quality of the samples in the gel, mRNA was used to synthesize the complementary DNA (cDNA) using OligodT $_{20}$ and Invitrogen SuperScript ${ }^{\circledR}$ III Reverse Transcriptase Kit (Life TechnologiesTM) according to the manufacturer's specifications.

\section{Cloning and Expression on K. pastoris}

Beauveria bassiana cDNA was used as template for PCR amplification of the gene encoding $B$. bassiana Lipase A (Bbla) using primers - BblAF, (5' NNNNNNCTCGAGAAAAGAGAGGCTGAAGCTCTTTCTGC GGACATTGACGG-3) and BblAR, (5'-NNNNNNGAATTCAA CATCCATACTCTCAGCAAGAAG CTT-3). The underlined sequences correspond to the XhoI and EcoRI sites, respectively. The full-length BblA coding sequence was PCR amplified by 
heating at $95^{\circ} \mathrm{C}$ for $10 \mathrm{~min}$, followed by 35 cycles of $95^{\circ} \mathrm{C}$ for $15 \mathrm{~s}, 52^{\circ} \mathrm{C}$ for $40 \mathrm{~s}, 72^{\circ} \mathrm{C}$ for $3 \mathrm{~min}$ and final incubation at $72^{\circ} \mathrm{C}$ for $7 \mathrm{~min}$. The PCR product was purified and digested with XhoI and EcoRI and cloned into the expression plasmid pPIC9K (Invitrogen, Nærum, Denmark) to produce the recombinant protein fused to the $\alpha$-factor secretion signal and to the 6 His extension at the $\mathrm{N}$ - and C-terminus, respectively (FonsecaMaldonado et al., 2013). The resulting construct (pPIC9CT-BblA) was transformed into electrocompetent DH5 $\alpha$ Escherichia coli, and isolated plasmid DNA was purified and the nucleotide sequence determined. The BbLA nucleotide sequence was analyzed using the available tools at http://www.expasy.org/.BblA (Xiao et al., 2012), and was deposited in the GenBank database under accession number XM_008603978.1.

The pPIC9CT-Bbla $(5 \mu \mathrm{g})$ was linearized with MssI (PmeI) (Thermo Scientific) and used to transform competent cells of the strain $K$. pastoris GS115 by electroporation at $1720 \mathrm{~V}$, $5.5 \mathrm{~ms}$ (T), using an electroporator Eporator (Eppedorf ${ }^{\circledR}$, USA). K. pastoris GS115/pPIC9CTBbla recombinants were grown on solid Minimal Dextrose (MD) plate medium for 3 days. Ninetysix colonies were transferred to Minimal Methanol Tributyrin plate medium (MMT - 1.34\% Yeast Nitrogen Base without amino acids [YNB], $1 \%$ tributyrin and $1.5 \%$ agar sterile medium added with $1 \%$ methanol when the culture medium was at $40^{\circ} \mathrm{C}$ ) and incubated for approximately 3 days at $30^{\circ} \mathrm{C}$ until halos of tributyrin hydrolysis appeared.

Three colonies that produced halo were inoculated into $100 \mathrm{~mL}$ buffered minimal glycerol medium (1.34\% YNB; $4.10^{-5} \%$ biotin; $100 \mathrm{mM}$ phosphate buffer, $\mathrm{pH} 6.0 ; 1 \%$ glycerol), and cultured in an orbital shaker $(200 \mathrm{rpm})$ at $30^{\circ} \mathrm{C}$. After $16 \mathrm{~h}$, the cells were collected and resuspended in $100 \mathrm{~mL}$ buffered methanol-complex medium (BMM - 1.34\% YNB; $4.10^{-5} \%$ biotin; $100 \mathrm{mM}$ phosphate buffer, $\mathrm{pH}$ 6.0) in an Erlenmeyer flask of $1 \mathrm{~L}$, with addition of $1 \%$ methanol every $24 \mathrm{~h}$. Culture was incubated for up to $144 \mathrm{~h}$ at $30^{\circ} \mathrm{C}$ and $200 \mathrm{rpm}$, the culture medium was collected by centrifugation and the production of the recombinant protein was analyzed by SDS-PAGE (Laemmli, 1970) and by quantification of lipase activity. The effect of the induction-time and culture medium composition was evaluated in culture media MM (1:34\% YNB, $1 \%$ methanol added every $24 \mathrm{~h}$ ), YPM (1\% yeast extract and $2 \%$ peptone added $1 \%$ methanol added every $24 \mathrm{~h}$ ) and BMM.

\section{Protein Purification}

Culture supernatants of BbLA-G2 transformant was concentrated and buffer exchanged using Hollow Fiber Cartrige, 50000 MMWC, in QuixStand Benchtop (GE Healthcare Bio-Sciences AB, Uppsala, Sweden) concentration system. Concentrated BbLA was purified by two protocols: (I) BbLA, added $500 \mathrm{mM} \mathrm{NaCl}$, was purified by IMAC-Cu ${ }^{2+}$. Resin was previously equilibrated with $500 \mathrm{mM} \mathrm{NaCl}$ in $10 \mathrm{mM}$ phosphate buffer, $\mathrm{pH}$ 7.0. Proteins were eluted with $250 \mathrm{mM}$ Imidazol and $500 \mathrm{mM} \mathrm{NaCl}$ in $10 \mathrm{mM}$ phosphate buffer, $\mathrm{pH}$ 7.0. (II) BbLA in $10 \mathrm{mM}$ phosphate buffer was purified by hydrophobic chromatography on Octyl-sepharose resin. BbLA was eluted with increased Triton X-100 concentrations up to $1 \%$. In both protocols, fractions containing enzyme were dialyzed in
$10 \mathrm{mM}$ phosphate buffer. Protein purity was checked using 12\% SDS-PAGE, and protein concentration was assayed according to Bradford (1976) using bovine serum albumin as the standard.

\section{Enzymatic Assays and Enzymatic Characterization}

The catalytic activity assay, modified from Moreno-Perez et al. (2014), used a spectrophotometer with a thermostated cell and continuous magnetic stirring $(500 \mathrm{rpm})$ for $2 \mathrm{~min}$. Reactions were initialized by mixing $0.1 \mathrm{~mL}$ of the soluble BbLA or its immobilized preparations (suspension) were added to $2.0 \mathrm{~mL}$ of the $p \mathrm{NPB}$ solution $(2.0 \mathrm{mM} p$-nitrophenyl butyrate $(p \mathrm{NPB})$ in $0.05 \%$ Triton $\mathrm{X}-100$ and $25 \mathrm{mM}$ sodium phosphate at $\mathrm{pH} 7.0)$ at $40^{\circ} \mathrm{C}$. The increase in absorbance at $380 \mathrm{~nm}$ $\left(\varepsilon=4.430 \mathrm{M}^{-1} \mathrm{~cm}^{-1}\right.$ ) resulting from $p N P$ release was used to calculate enzymatic activity, given as $\mu \mathrm{mol}$ of $p$ NPB hydrolyzed per minute per $\mathrm{mL}$ of enzyme $(\mathrm{U} / \mathrm{mL})$ under the described conditions. Kinetic parameters were determined for $p \mathrm{NPB}$ hydrolysis, in the best conditions for BbLA activity. Software GraphPad Prism 6.0 was used to calculate the $V_{\max }$ and $\mathrm{k}_{\mathrm{M}}$ values.

The evaluation of the effect of surfactants on BbLA activity was made with $0.05 \%$ Triton X-100 was replaced by $0.05 \%$ Tween 20, Tween 80, Tergitol 40, CTAB or SDS. A control without surfactant was performed. Temperature and $\mathrm{pH}$ effects were evaluated by a $2^{2}$ Rotational Central Composite Design. The $\mathrm{pH}$ (and encoded) values tested were $4.59(-1.41), 5.0$ $(-1), 6.0(0), 7.0(+1)$ and $7.41(+1.41)$, and temperature (and encoded) values were $35.9^{\circ} \mathrm{C}(-1.41), 40^{\circ} \mathrm{C}(-1), 50^{\circ} \mathrm{C}(0)$, $60^{\circ} \mathrm{C}(+1)$ and $64.1^{\circ} \mathrm{C}(+1.41)$. Enzyme activity was evaluated discontinuously, where $50 \mu \mathrm{L}$ of the reaction was added to $50 \mu \mathrm{L}$ of supersaturated sodium tetraborate, after 1 and 2 min reaction. $p$ NPB hydrolysis was measured at $410 \mathrm{~nm}\left(\varepsilon=3.420 \mathrm{M}^{-1} \mathrm{~cm}^{-1}\right)$ in a SpectraMax 96-well plate Spectrophotometer (Molecular Devices). Three central point repetitions were added to verify the analysis reproducibility. A confidence level of $95 \%$ was considered in the analysis of the variables effect. A polynomial equation was constructed for response surface analysis, and the Student's $t$-test was used to verify the statistical significance of the regression coefficients. Statistical software Statistica v.12.0 was used to analyze the experimental data.

\section{Deglycosylation of Recombinant Protein by Endoglycosidase $\mathbf{H}$}

Deglycosylation of purified recombinant BbLA was performed by Endo $\mathrm{H}_{\mathrm{f}}$ (BioLabs, New England), with modifications to the manufacturer's protocol. The deglycosylation reaction comprised $45 \mu \mathrm{L}$ purified BbLA (80 ug protein) added to $5 \mu \mathrm{L} 10 \mathrm{X}$ denaturation buffer, mixed and heated at $100^{\circ} \mathrm{C}$ for $10 \mathrm{~min}$. Thereafter, $10 \mu \mathrm{L}$ G5 reaction buffer, $0.5 \mu \mathrm{L}$ of Endo $\mathrm{H}_{f}$ and $39.5 \mu \mathrm{L}$ of MilliQ $\mathrm{H}_{2} \mathrm{O}$ were added. The reaction was incubated at $37^{\circ} \mathrm{C}$ for $24 \mathrm{~h}$. Deglycosylation was evaluated using $12 \%$ SDS-PAGE.

\section{Spectroscopy}

Circular dichroism spectra between 190 and $250 \mathrm{~nm}$ (far-UV CD) were measured using a JASCO 810 spectropolarimeter (JASCO, 
Tokyo, Japan) at a protein concentration of $0.04 \mathrm{mg} / \mathrm{mL}$ in $0.1 \mathrm{~cm}$ path-length quartz cuvettes in $10 \mathrm{mM}$ phosphate buffer $\mathrm{pH}$ 7.0. The mean of four accumulated spectra was measured, from which the spectrum of a buffer blank was subtracted.

\section{Three-Dimensional Model of the BbLA}

The secondary sequence was inferred using the PDBSum platform ${ }^{1}$. Homology modeling method (Deane and Blundell, 2003) was carried out using the I-Tasser (Zhang, 2008) ${ }^{2}$. Based on the X-ray structure of EstA (PDB ID: 1UKC), which was selected as template because an X-ray structure of the more homologue lipase from $B$. bassiana was not available. The primary sequence of lipases (BbLA and EstA) were aligned with highest scoring lipase (B. bassiana ARSEF 2860) obtained by BLAST using MUSCLE 3.6 (Edgar, 2004), to recognize the catalytic triad. The model quality structure was evaluated through PROCHECK program (Laskowski et al., 1993). The figures were generated using PyMOL ${ }^{3}$.

\section{BbLA Immobilization on Duolite A568 and Sepabeads-C18 Resins}

The BbLA crude extract was dialyzed and equilibrated in $10 \mathrm{mM}$ phosphate buffer, $\mathrm{pH}$ 7.0. A sample of $5 \mathrm{mg}$ protein BbLA solution was added to $1 \mathrm{~g}$ of support Duolite A568 (derivative named BbLA-Duolite) or Sepabeads-C18 (derivative named as BbLA-C18). The immobilization mixture was maintained at $\mathrm{pH}$ 7.0 , overnight, at $25^{\circ} \mathrm{C}$. The activity of the immobilized enzyme was measured by the $p \mathrm{NPB}$ assay.

\section{Enzymatic Synthesis of Ethyl Esters of Omega-3 Fatty Acids}

Ethyl ester synthesis by BbLA was performed as described by Moreno-Perez et al. (2014). First, $0.26 \mathrm{~g}$ of dried immobilized lipase was added to the substrate solution containing $0.623 \mathrm{mmol}$ of sardine oil and $6.2 \mathrm{mmol}$ of ethanol dissolved in $4.11 \mathrm{~mL}$ cyclohexane. Second, $0.26 \mathrm{~g}$ of dry molecular sieves was added to the reaction mixture for the BbLA reaction in the absence of water. The final concentration of sardine oil in the solution was $125 \mathrm{mM}$, and the reaction was carried out at $25^{\circ} \mathrm{C}$. Aliquots of $100 \mu \mathrm{L}$ were withdrawn every $24 \mathrm{~h}$, and diluted in $300 \mu \mathrm{L}$ of HPLC mobile phase. BbLA-derivatives used in this experiment were dried using acetone solutions in water with increasing concentrations of acetone up to $100 \%$. Product formation was monitored by HPLC, where the control consisted of the same quantities of reagents, but without the presence of catalyst.

\section{HPLC Analysis}

Reactants and products were analyzed using a reverse-phase column (Ultrabase-C8, $150 \mathrm{~mm} \times 4.6 \mathrm{~mm}, 5 \mu \mathrm{m}$ ) by RPHPLC (Spectra Physic SP 100 coupled with a UV detector Spectra Physic SP 8450). Products were eluted at a flow rate of $1.5 \mathrm{~mL} / \mathrm{min}$ with acetonitrile/water/ $\mathrm{CH}_{3} \mathrm{COOH}(80: 20: 0.1$

\footnotetext{
${ }^{1}$ http://www.ebi.ac.uk/pdbsum/

${ }^{2}$ http://zhanglab.ccmb.med.umich.edu/I-TASSER/

${ }^{3}$ http://www.pymol.org
}

$\mathrm{v}: \mathrm{v}), \mathrm{pH}$ 3. The UV detection was performed at $215 \mathrm{~nm}$. Product yields were calculated from the pure peak areas of known quantities of EPA ethyl ester [retention time (RT) of $9 \mathrm{~min}$ ] and docosahexaenoic acid (DHA) ethyl ester (RT of $12 \mathrm{~min})$.

\section{Reproducibility of the Results}

All data are the mean of at least three independent experiments.

\section{Results and Discussion}

\section{Cloning and Expression of Beauveria bassiana Lipase A in Komagataella pastoris}

A putative triacylglycerol lipase gene (GenBank access number EJP62207.1) was chosen from several genes described as lipase or lipase-like in the $B$. bassiana genome. The gene, named $B b l A$ (Beauveria bassiana lipase $A$ ) is 1,641 bp long and encodes a protein with 546 amino acid residues, including a 19-amino acid signal peptide. BbLA has a theoretical molecular weight and $p I$ of $59.58 \mathrm{kDa}$ and 5.22 , respectively. The BblA cDNA without the signal peptide sequence was obtained by RTPCR from B. bassiana cDNA with primers BblAF and BblAR. $B b l A$ was cloned into the expression vector pPIC9k_CT inframe with the yeast $\alpha$-factor secretion signal. The resulting plasmid was sequenced and named pPIC9CT-BblA. BblA is translated into a 554 amino acids protein (including a His tag at the C-terminus), which has the catalytic triad and the common consensus sequence (G-X-S-X-G) for lipases (Figure 1).

Linearized pPIC9CT-BblA was used to transform K. pastoris GS115. Ninety-six transformants were screened for the presence of hydrolysis halos in MM solid medium containing methanol and tributyrin (Figure 2). Three colonies that showed a higher $\mathrm{D} / \mathrm{d}$ ratio $(\mathrm{D} / \mathrm{d})$ were selected. These clones were called BbLA F5, BbLA G2 and BbLA H1.

After $120 \mathrm{~h}$ induction with $1 \%$ methanol in liquid medium, the culture supernatants from the three clones showed similar lipase activity (Figure 3A). Transformant BbLA G2 was chosen for further studies because it showed the highest ratio $\mathrm{D} / \mathrm{d}$ (Figure 2). BbLA showed better lipase expression in BMM medium after $120 \mathrm{~h}$ of methanol induction, demonstrating that buffering the culture medium and long induction times favor protein expression (Figures 3B,C).

\section{Purification and Characterization of BbLA}

Beauveria bassiana lipase A was purified by two protocols. The first protocol employed IMAC- $\mathrm{Cu}^{2+}$, which exploited the addition of a His-tag at the N-terminal of BbLA. The second protocol involved hydrophobic interaction chromatography using Octyl-sepharose at low ionic strength, which exploited the fact that BbLA is a lipase and therefore has a strongly hydrophobic substrate binding region. Both these protocols resulted in purified BbLA (Figure 4). IMAC- $\mathrm{Cu}^{2+}$ showed a slightly higher purification factor, while the Octyl-sepharose chromatography showed higher recovery (Table 1). Therefore, 


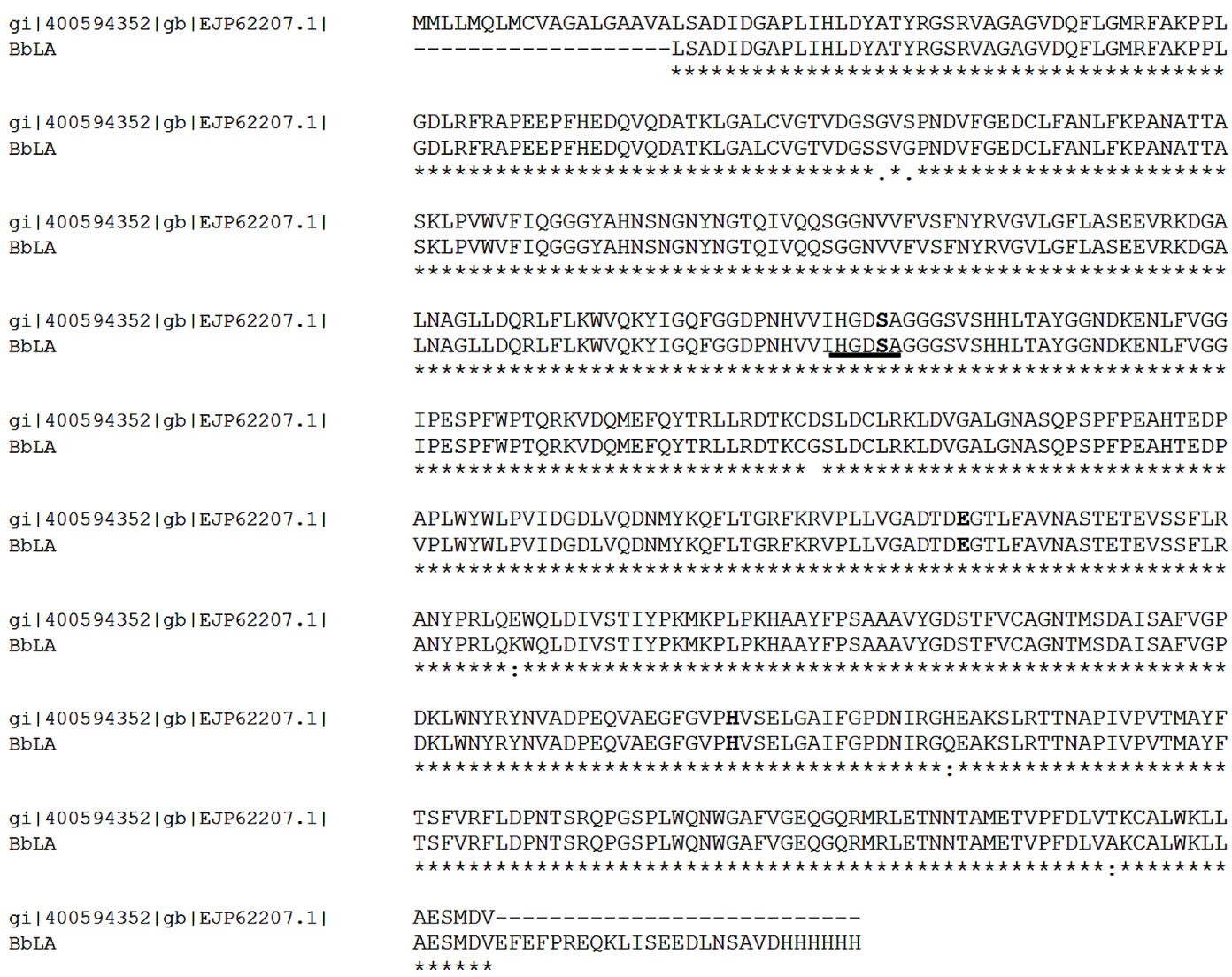

gi | 400594352 | gb | EJP62207.1 | BbLA

gi | 400594352 | gb | EJP62207.1 | BbLA

gi | 400594352 | gb | EJP62207.1 | BbLA

gi | 400594352 | gb | EJP62207.1 | BbLA

gi | 400594352 | gb | EJP62207.1 | $\mathrm{BbLA}$

gi | 400594352 | gb | EJP62207.1 | BbLA

gi | 400594352 | gb | EJP62207.1 | BbLA

gi | 400594352 | gb | EJP62207.1| BbLA

gi|400594352|gb|EJP62207.1| BbLA

gi | 400594352 | gb | EJP62207.1 | BbLA

MMLLMQLMCVAGALGAAVALSADIDGAPLIHLDYATYRGSRVAGAGVDQFLGMRFAKPPI -LSADIDGAPLIHLDYATYRGSRVAGAGVDQFLGMRFAKPPL

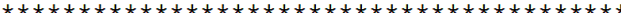

GDLRFRAPEEPFHEDQVQDATKLGALCVGTVDGSGVSPNDVFGEDCLFANLFKPANATTA GDLRFRAPEEPFHEDOVODATKLGALCVGTVDGSSVGPNDVFGEDCLFANLFKPANATTA

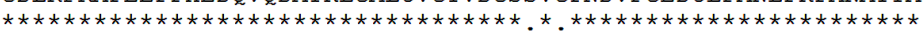

SKLPVWVFIQGGGYAHNSNGNYNGTQIVQQSGGNVVFVSFNYRVGVLGFLASEEVRKDGA SKLPVWVFIQGGGYAHNSNGNYNGTQIVQQSGGNVVEVSFNYRVGVLGFLASEEVRKDGA

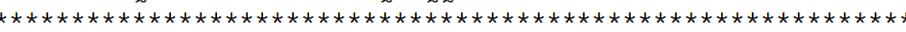

LNAGLLDQRLFLKWVQKYIGQFGGDPNHVVIHGDSAGGGSVSHHLTAYGGNDKENLFVGG LNAGLLDQRLFLKWVQKY IGQFGGDPNHVVIHGDSAGGGSVSHHLTAYGGNDKENLFVGG

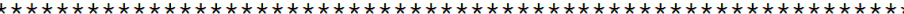

IPESPFWPTQRKVDQMEFQYTRLLRDTKCDSLDCLRKLDVGALGNASQPSPFPEAHTEDP IPESPFWPTQRKVDQMEFQYTRLLRDTKCGSLDCLRKLDVGALGNASQPSPFPEAHTEDP

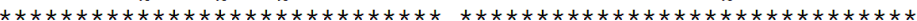

APLWYWLPVIDGDLVQDNMYKQFLTGRFKRVPLLVGADTDEGTLFAVNASTETEVSSFLR VPLWYWLPVIDGDLVQDNMYKQFLTGREKRVPLLVGADTDEGTLEAVNASTETEVSSFLR

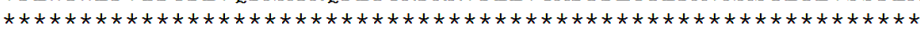

ANYPRLQEWQLDIVST IYPKMKPLPKHAAYFPSAAAVYGDSTFVCAGNTMSDAISAFVGP ANYPRLQKWQLDIVST IYPKMKPLPKHAAYFPSAAAVYGDSTFVCAGNTMSDAISAFVGP

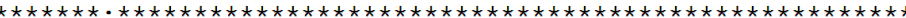

DKLWNYRYNVADPEQVAEGFGVPHVSELGAIFGPDNIRGHEAKSLRTTNAPIVPVTMAYF DKLWNYRYNVADPEQVAEGFGVPHVSELGAIFGPDNIRGQEAKSLRTTNAPIVPVTMAYF

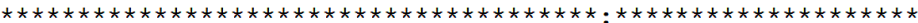

TSFVRFLDPNTSRQPGSPLWQNWGAFVGEQGQRMRLETNNTAMETVPFDLVTKCALWKLL TSFVRFLDPNTSRQPGSPLWONWGAFVGEOGORMRLETNNTAMETVPFDLVAKCALWKLI

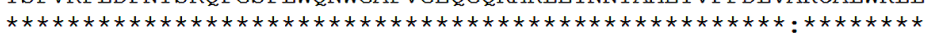

AESMDV

AESMDVEFEFPREQKLISEEDLNSAVDHHHHHH $\star \star \star \star * *$

FIGURE 1 | Amino acid sequence alignment of BbLA with GenBank accession number EJP62207. The catalytic triad is highlighted in bold and the conserved pentapeptide including the catalytic serine is underlined in black. The Bb/A gene was translated from the nucleotide sequence obtained from the cloned gene. The alignment was generated with Standard Protein BLAST tool.

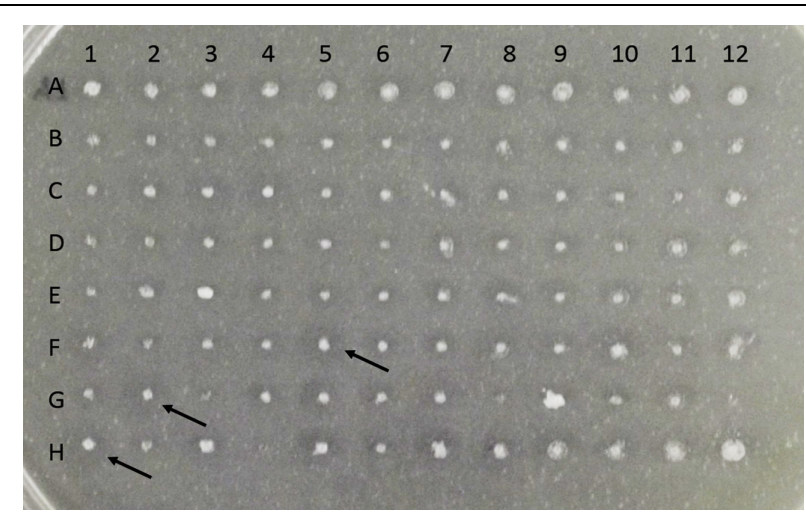

FIGURE 2 | Screening for expression of BbLA in Komagataella pastoris on solid BMM Tributyrin medium. Colonies were grown at $30^{\circ} \mathrm{C}$ for $72 \mathrm{~h}$. Arrows indicate the three colonies (F5, G2, and $\mathrm{H} 1$ ) selected for further expression analysis.

the sample obtained from Octyl-sepharose purification was used for enzymatic characterization assays.

Beauveria bassiana lipase A was activated by Triton X-100, Tween 20, Tween 80 , Tergitol and CTAB, but was completely inactivated by SDS. The best condition for BbLA activation was with $0.05 \%$ Triton X-100 (Supplementary Figure S1).

A CCRD was used to analyze the optimal temperature and $\mathrm{pH}$ for BbLA reaction. For BbLA activity, the two variables showed a linear effect and temperature showed a quadratic effect (Figure 5A). A reduced second order model for BbLA activity is described by equation 1 .

$$
\operatorname{Activity}(U / m L)=15.96-2.43(T)-5.09(T)^{2}-6.56(p H)^{2}
$$

where, $\mathrm{T}$ and $\mathrm{pH}$ are encoded temperature and $\mathrm{pH}$ values, respectively.

Table 2 shows ANOVA results from reduced models generated. The determination coefficient was $0.9112 . F_{\text {calculated }}$ value was higher than $F_{\text {listed }}$ (Table 2). Therefore, this model was considered predictive and statistically significant at $95 \%$ confidence level. This result was analyzed by response surface methodology, and generated a 3D surface graph (Figure 5B). These results led to the estimation of ideal temperature and $\mathrm{pH}$ reaction conditions for $\mathrm{BbLA}$, which were $50^{\circ} \mathrm{C}$ and $\mathrm{pH} 6.0$, corresponding to the central points assayed.

The $\mathrm{K}_{\mathrm{M}}, \mathrm{V}_{\text {max }}, \mathrm{k}_{\mathrm{cat}}$ and $\mathrm{K}_{\mathrm{cat}} / \mathrm{K}_{\mathrm{M}}$ of BbLA recombinant against $p \mathrm{NPB}, \mathrm{pH} \quad 6.0$ at $50^{\circ} \mathrm{C}$, were $0.5546 \mu \mathrm{M}$, 

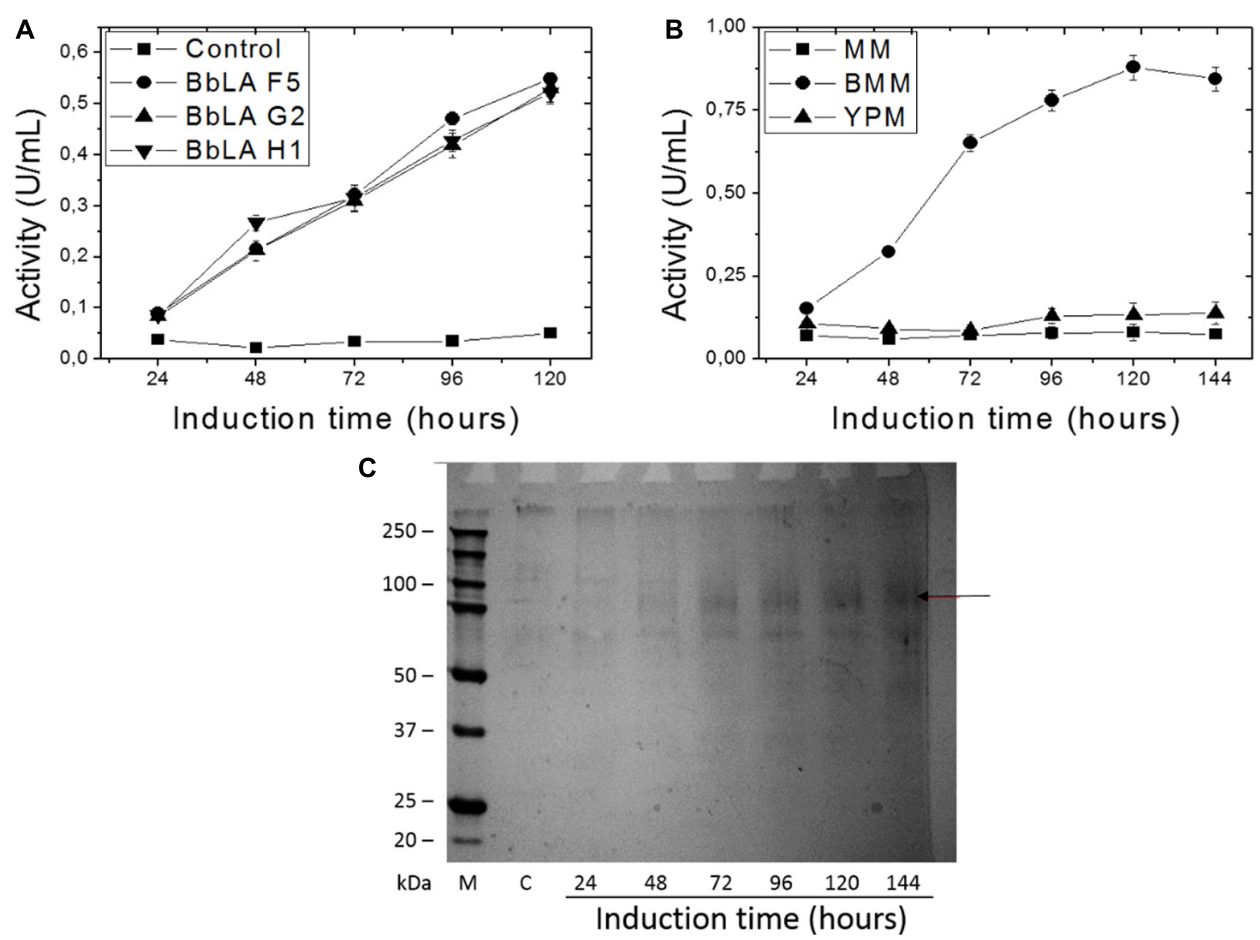

FIGURE 3 | Recombinant BbLA expression in K. pastoris. (A) Methanol induction of BbLA colonies F5, G2, and H1; (B) BbLA expression in different culture medium of the BbLA-G2 colony; (C) SDS-PAGE electrophoresis of BbLA expressed by BbLA-G2 colony over increasing time intervals on methanol induction. The control was $\mathrm{K}$. pastoris transformed with empty vector. $\mathrm{M}$, molecular weight marker; $\mathrm{C}$, control. Cultures were incubated at $30^{\circ} \mathrm{C}$, with 200 rpm. The arrow indicates the purified lipase.
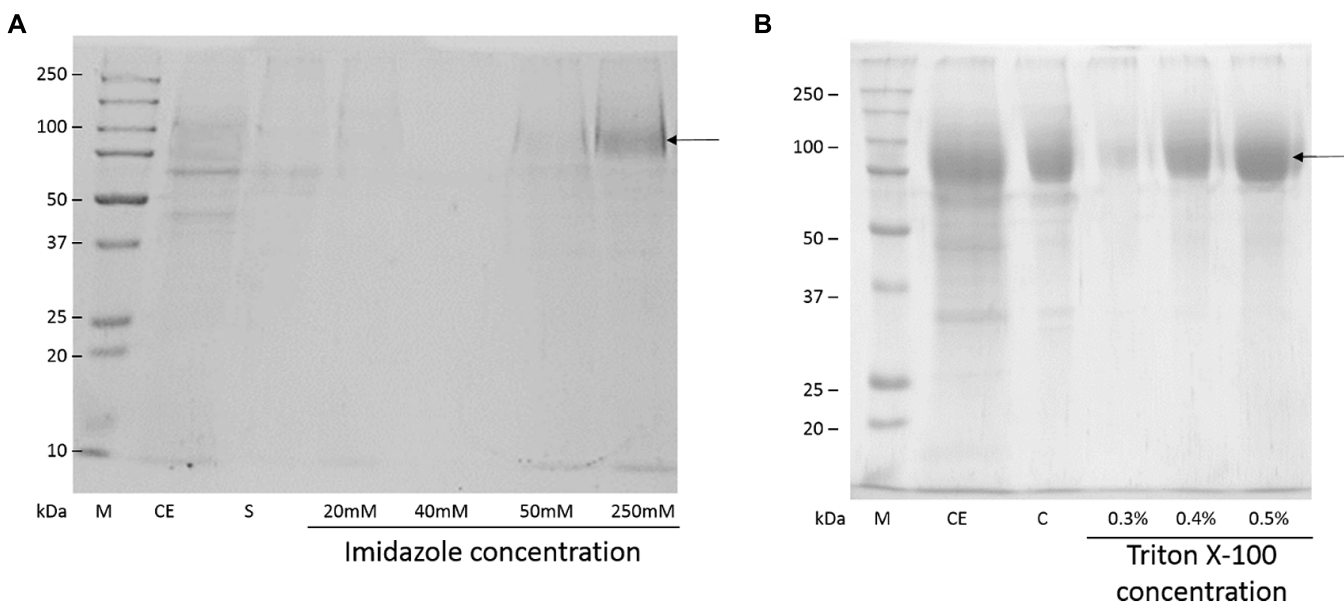

FIGURE 4 | Sodium dodecyl sulfate-polyacrylamide gel electrophoresis electrophoresis of BbLA purification. (A) Purification in IMAC - Cu²+.

(B) Purification on Octyl-sepharose. M, molecular weight marker; CD, crude extract of BbLA; S, IMAC supernatant; C, concentrated BbLA. The arrows indicate the band corresponding to BbLA. See Methods section for further experimental details.

85.67 $\mu$ mols.min ${ }^{-1} . \mathrm{mg}^{-1}, \quad 7.139 \times 10^{4} . \mathrm{s}^{-1}, \quad$ and $1.29 \times 10^{11} \cdot \mathrm{M}^{-1} \cdot \mathrm{s}^{-1}$, respectively (Table 3 ). Hill coefficient was higher than 1.0, which suggested that BbLA can be an allosteric enzyme. Allosteric lipase modulation is not common, but it is described as possible and biologically relevant (Kohler and Wunsch, 2007).

\section{BbLA Deglycosylation}

Beauveria bassiana lipase A presents no potential site for $O$-glycosylation, but includes six potential $N$-glycosylation sites. Purified BbLA showed a diffuse band in SDS-PAGE centered around $78 \mathrm{kDa}$, which after treatment with EndoHf, an endoglucanase that cleaves $\mathrm{N}$-glycosylated oligosaccharides, 
TABLE 1 | Beauveria bassiana lipase A purification by immobilized metal $\left(\mathrm{Cu}^{2+}\right)$ affinity chromatography (IMAC) and hydrophobic interaction (Octyl-sepharose) chromatography.

\begin{tabular}{lccc}
\hline Sample & $\begin{array}{c}\text { Specific activity } \\
\text { (U/mg) }\end{array}$ & Purification factor & $\begin{array}{c}\text { Recovery } \\
\text { (\%) }\end{array}$ \\
\hline Crude extract & 8.59 & 1 & 100 \\
IMAC - Cu ${ }^{2+}$ & 131.50 & 15.30 & 39.13 \\
Octyl-Sepharose & 119.18 & 13.88 & 75.58 \\
\hline
\end{tabular}

shifts to $60 \mathrm{kDa}$ (Figure 6). Assuming that these forms represent the glycosylated and deglycosylated forms, respectively, then the saccharide content of the glycosylated BbLA is approximately $30 \%$.

\section{Molecular Modeling}

The far-UV circular dichroism spectrum of purified BbLA at $\mathrm{pH} 7.0$ presents a maximum at $194 \mathrm{~nm}$ and a minimum at 207 and $220 \mathrm{~nm}$, which are spectral features typical of proteins rich in $\alpha$-helix (Figure 7A). Nevertheless, the spectral feature generated is not characteristic of proteins exclusively formed by $\alpha$-helices.

Aspergillus niger esterase (EstA, PDB code Q6ED33) (Bourne et al., 2004), shares $55.56 \%$ identity with BbLA and was used as a template for structural modeling of the BbLA on the I-TASSER platform. The secondary structure topology is showed in Figure 7B for the sequence length of 554 amino acids, where 61 residues are found in beta strands (forming $\beta$-sheets), 153 in $\alpha$-helices, 14 in 3-10 helix and 326 in other secondary structure motifs such as beta hairpins, beta bulges, beta turns, and gamma turns. The model of the enzyme is a monomer presenting a $\alpha / \beta$ fold comprised of four central stranded $\beta$ sheet flanked by $22 \alpha$-helices. The superposition between BbLA and EstA structures (Figure 8A) generates an RMSD score of 0.37 . The catalytic triad is formed by Ser-Glu-His (Figure 8B).

\section{BbLA Immobilization and Application of BbLA-Derivatives in Fish Oil Ethanolysis}

Beauveria bassiana lipase A was immobilized on Duolite and C18-Sep by reversible anionic and hydrophobic interaction, respectively. Derivatives generated from this immobilization were named BbLA-Duolite and BbLA-C18, and had 8.65 and $12.35 \mathrm{U} / \mathrm{g}$ of support, respectively. Duolite and C18-Sep immobilized 83 and $98 \%$ of the BbLA present in the crude extract. BbLA-Duolite and BbLA-C18 were dried and added to a reaction medium free of water, in order to favor the transesterification reaction.

Eicosapentaenoic and DHA acids are abundant in sardine oil, and fatty acid ester formation after $24 \mathrm{~h}$ reaction revealed BbLA-C18 produced 7.35-fold more EPA-ester and 13.61-fold more DHA-ester than produced by BbLA-Duolite after $48 \mathrm{~h}$ reaction. However, BbLA-Duolite was more selective than BbLAC18 (Table 4).
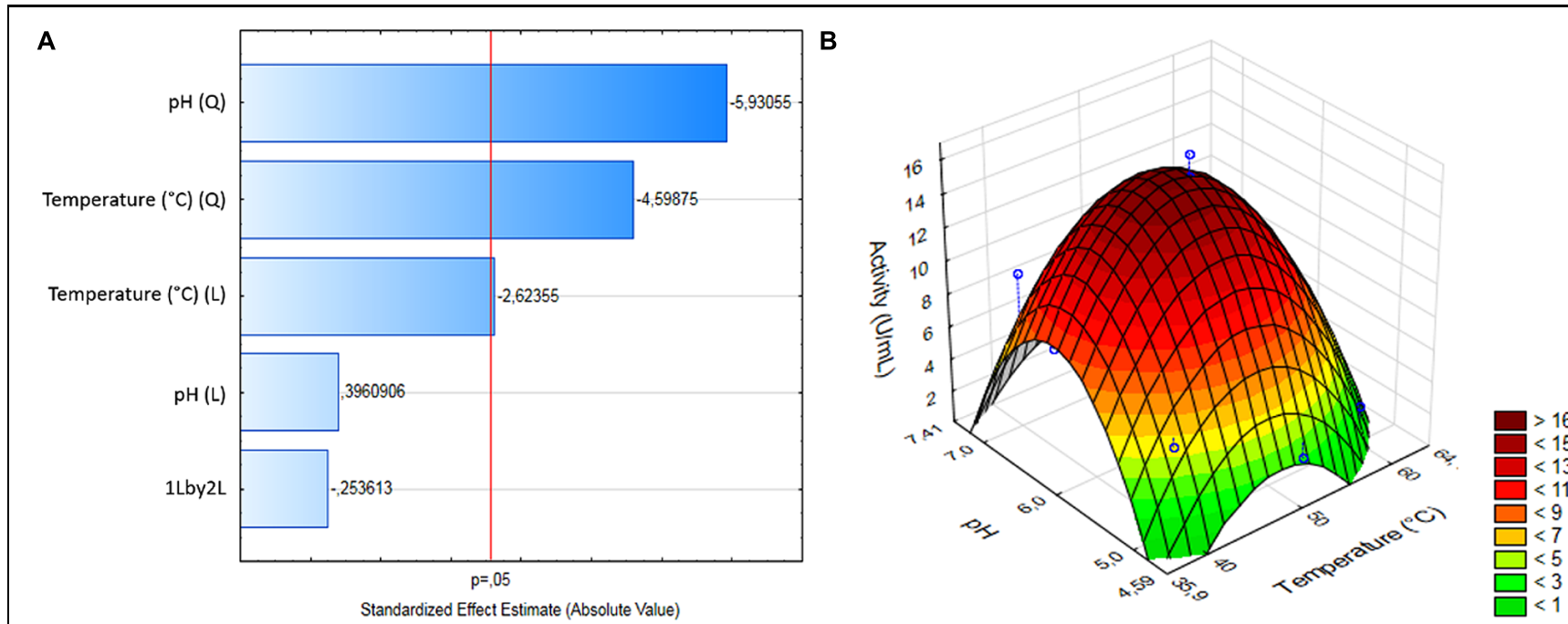

FIGURE 5 | Experimental design for assessing pH and temperature effects on BbLA activity. (A) Pareto plot for CCDR. (B) Surface response for pH and temperature variables. The analysis was performed by Statistica 12.0 software.

TABLE 2 | Central composite rotational design ANOVA for pH and temperature effects on the BbLA activity.

\begin{tabular}{|c|c|c|c|c|c|}
\hline Variation source & Sum of square (SS) & Degree of freedom (DF) & Mean of Square (MS) & $F_{\text {calculated }} \mathrm{MS}_{\mathrm{R}} / \mathrm{MS}_{\mathrm{R}}$ & $\boldsymbol{F}_{\text {listed }} \boldsymbol{F}_{95 \%, \mathrm{DFR}, \mathrm{DFr}}$ \\
\hline Regression (R) & 354.17 & 3 & 118.057 & 23.898 & 4.35 \\
\hline Residue (r) & 34.59 & 7 & 4.94 & & \\
\hline Total (T) & 388.76 & 10 & & & \\
\hline
\end{tabular}

$R^{2}=0.9112$ 


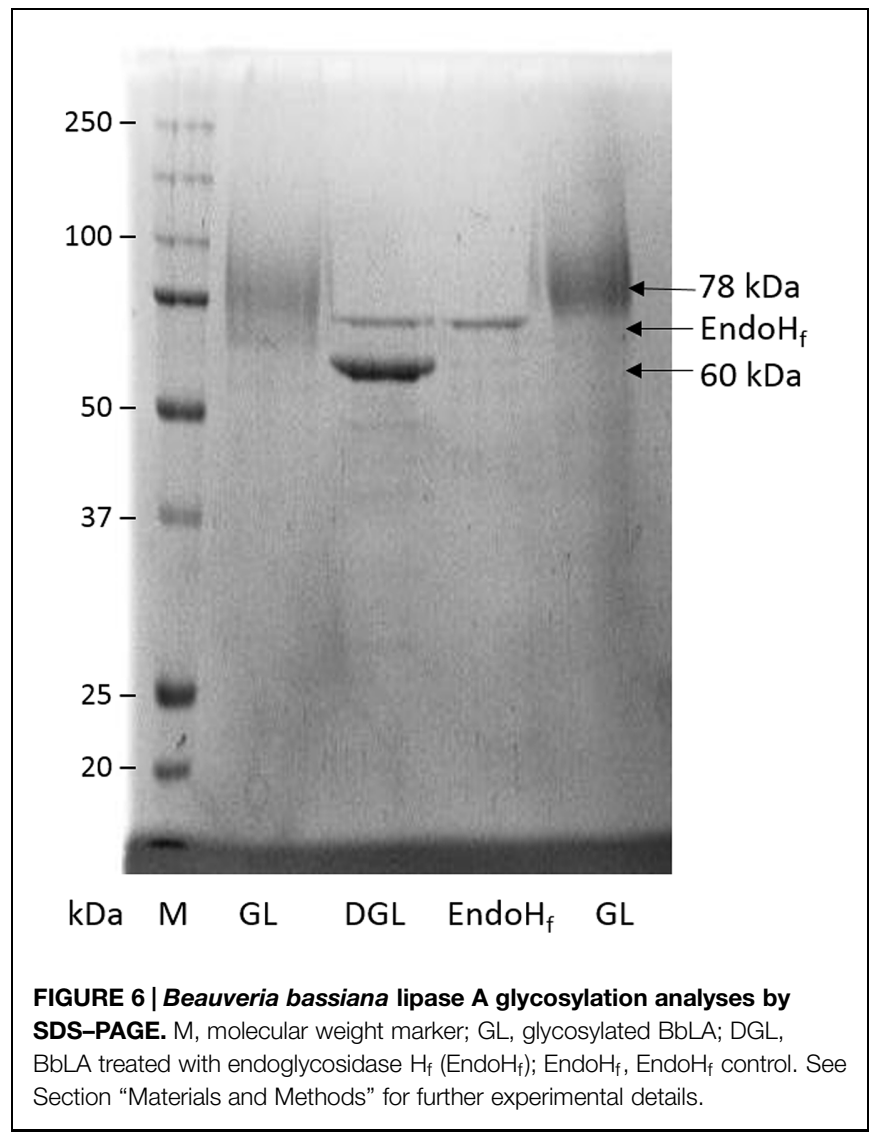

\section{Discussion}

$B b l A$ is a $B$. bassiana putative triacylglycerol lipase gene. This gene encodes a protein with 546 amino acid residues, $59.58 \mathrm{kDa}$ and PI 5.22. BbLA protein has the catalytic triad and the common consensus sequence (G-X-S-X-G) for lipases. This sequence was the only consensus sequence identified in studies on nonredundant sequences of lipases deposited in the public data banks. The serine residue present in this pentapeptide is the nucleophilic amino acid present in the catalytic triad (Jaeger et al., 1994, 1999; Schrag and Cygler, 1997; Lotti and Alberghina, 2007).

BbLA F5, BbLA G2 and BbLA H1 clones presented similar lipase activity. BbLA G2 showed better lipase expression in BMM medium after $120 \mathrm{~h}$ of methanol induction. In comparison, Thermomyces lanuginosus lipase shows improved expression when grown in BMMY medium (similar to BMM, but including yeast extract) $\mathrm{pH} 7.0$, with $1.2 \%$ methanol added every $24 \mathrm{~h}$, and $144 \mathrm{~h}$ induction (Fang et al., 2014). These results corroborate those obtained in this work and demonstrate the importance of controlling the $\mathrm{pH}$ and induction over relatively long periods.

Beauveria bassiana lipase A was purified by affinity chromatography (IMAC-Cu ${ }^{2+}$ ) and hydrophobic interaction chromatography (Octyl-sepharose). The BbLA recovery after IMAC purification (39.13\%) was superior to that observed for GCLI (13\%) and GCLII (14\%) for IMAC purification of Geotrichum candidum lipase expressed in Saccharomyces cerevisiae (Bertolini et al., 1995). However, it was lower than the recovery obtained for Bacillus licheniformis lipase (64\%) also fused to a His-tag and expressed in Escherichia coli (Madan and Mishra, 2009). BbLA purified with OctylSepharose had $75.58 \%$ recovery. Under low ionic strength conditions, only proteins with large hydrophobic sites, such as lipases, adsorb to hydrophobic resins (Palomo et al., 2002, 2006; Mateo et al., 2007). Indeed, hydrophobic interaction chromatography is often used as one of the steps for lipase purification, such as lipases produced by Pseudomonas aeruginosa (Bertolini et al., 1995) e Staphylococcus warneri (Volpato et al., 2011).

Surfactants activation is common to lipases. Triton X-100, Tween 20, Tween 80, Tergitol and CTAB activated BbLA. While, SDS inactivated it. These results are similar to those previously reported in the literature, such as those obtained for Thermosyntropha lipolytica lipases $\mathrm{A}$ and $\mathrm{B}$, which are activated by sodium cholate, CTAB, Triton X-100, Tween 20, Tween 80 and SDS (Salameh and Wiegel, 2010). The lipase from Thermomyces lanuginosus was also activated by all the surfactants used, included SDS (Mogensen et al., 2005). On the other hand, Penicillium chrysogenum lipase was inhibited by almost all detergents used, including SDS, Triton X-100 and Tween 20, the only exception being cholic acid (Bancerz et al., 2005).

Central composite rotational design and response surface showed that the best temperature and $\mathrm{pH}$ reaction were $50^{\circ} \mathrm{C}$ and $\mathrm{pH} 6.0$, respectively. Similarly to the results presented in this work, the optimum conditions obtained for Penicillium verrucosum lipase activity (Kempka et al., 2008) were $44^{\circ} \mathrm{C}$ and $\mathrm{pH} 7.0$ and $40^{\circ} \mathrm{C}$ and $\mathrm{pH} 5.0$ for Penicillium sp. lipase (Wolski et al., 2009).

Beauveria bassiana lipase A expressed in $K$. pastoris is approximately $30 \% \mathrm{~N}$-glycosylated. The glycosylation of BbLA was higher than that observed for the Y. lipolytica Lip2, expressed in K. pastoris, which has $12 \%$ of its molecular weight corresponding to glycosylation (Wang et al., 2012). However, not all proteins expressed by $K$. pastoris are glycosylated. For example, two RCLs expressed in this system showed no evidence for glycosylation after treatment with EndoH (Yu et al., 2009).

Beauveria bassiana lipase A far-UV circular dichroism spectrum presented features typical of proteins rich in $\alpha$-helix. But BbLA is not exclusively formed by $\alpha$-helix, because the secondary structure topology showed that 61 amino acids residues would be in the $\beta$-sheet configuration. A similar structure is observed for other lipase enzymes from mammalian and bacterial origin, where the number of $\alpha$-helices and $\beta$-sheet differ from one species to another (Messaoudi et al., 2011).

Aspergillus niger esterase A (Bourne et al., 2004) was used as a template for structural modeling of the BbLA. Esterases (EC 3.1.1.1) and lipases (EC 3.1.1.3) can be differentiated on the basis of their substrate specificity and by comparison of sequence-related structural features. In contrast to esterases, lipases display a significant difference in the distribution of 
A

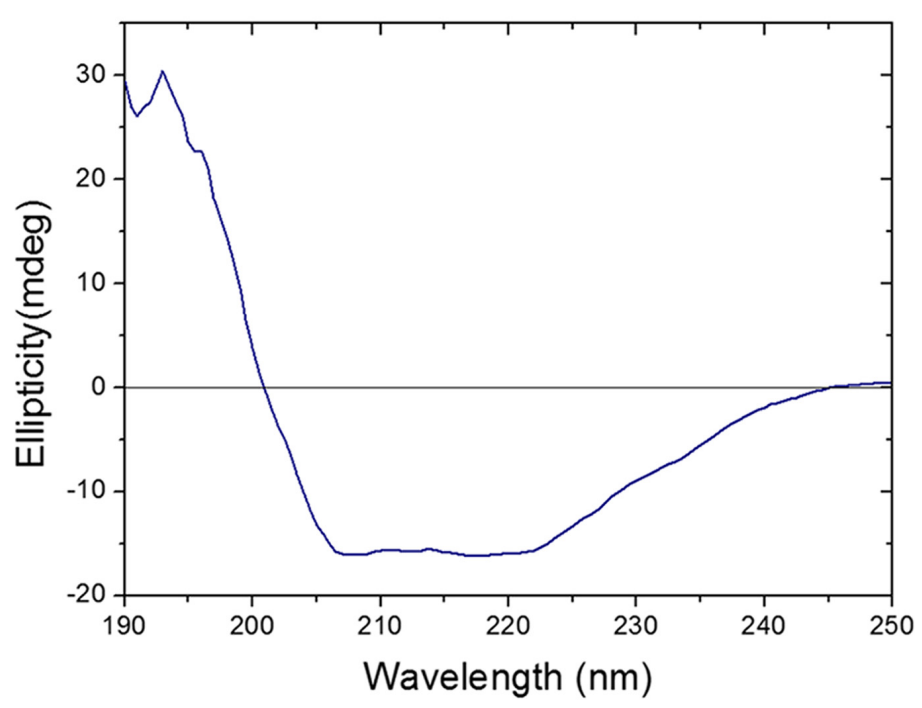

B

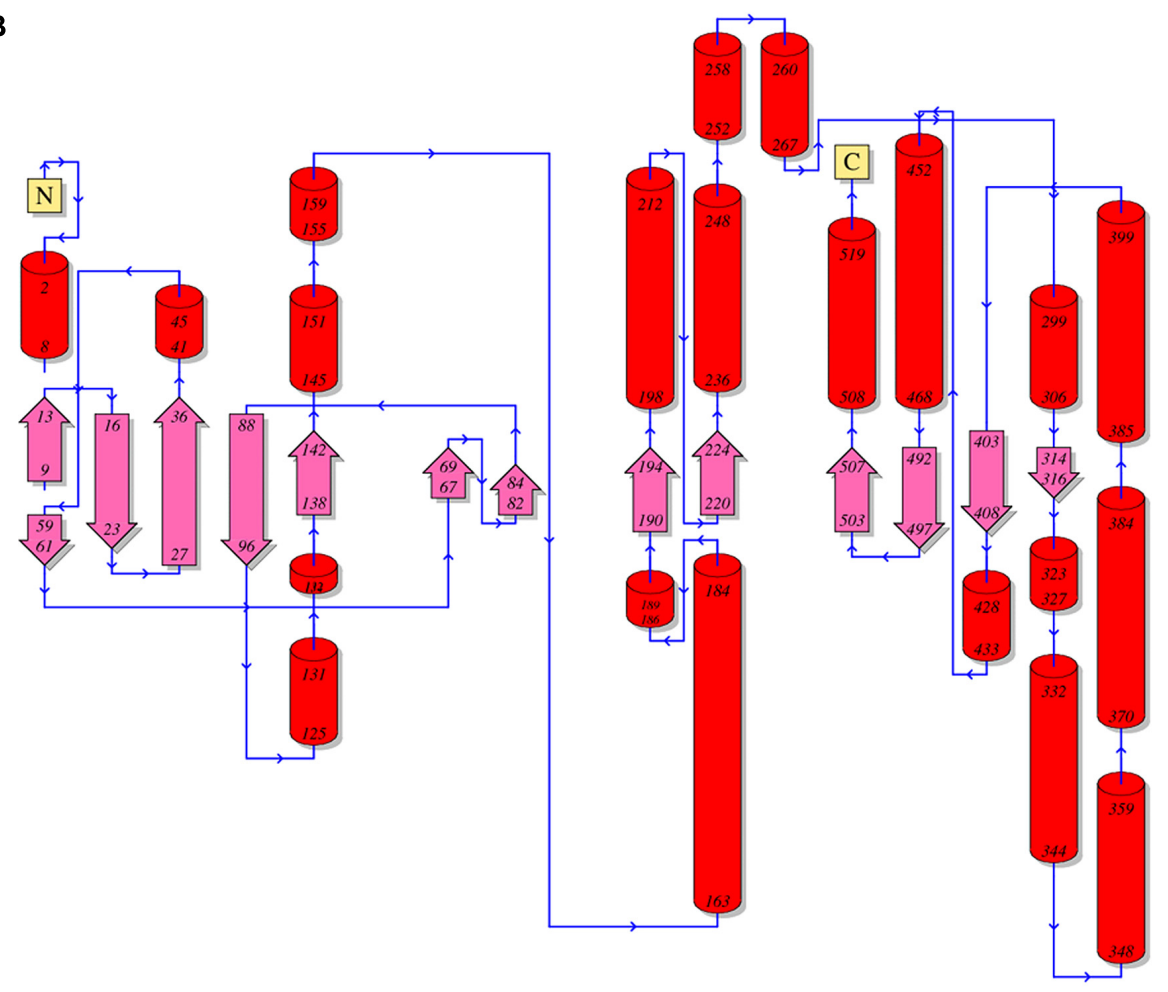

FIGURE 7 | Beauveria bassiana lipase A secondary structures. (A) Far-UV circular dichroism spectrum of BbLA. (B) Secondary structures of Beauveria bassiana Lipase A. The model was inferred by PDBSum (http://www.ebi.ac.uk/pdbsum/) (Laskowski et al., 1993) using the amino acid sequence. The numbers are regarding residues positions, red cylinders are $\alpha$-helices and pink arrow are $\beta$-strands. $\mathrm{N}, \mathrm{N}$-terminal and $\mathrm{C}, \mathrm{C}$-terminal.

hydrophobic amino acid residues in the vicinity of their active sites (Chahinian and Sarda, 2009). The catalytic triad formed by Ser-Glu-His is the same as that in the Geotrichum candidum lipase, where glutamic acid replacing the usual aspartate (Schrag et al., 1991).

The three-dimensional model of the BbLA has proportionally more $\alpha$-helix than $\beta$-sheet, but the two secondary structures are present. BbLA circular dichroism and molecular model are consistent with structures of lipases and esterases, because showed similar structure to $\alpha / \beta$ hydrolase. Despite the validation of structure through Ramachandran plot have presented less than $90 \%$ of residues in most favored regions. The predicted model is consistent with other lipases structures from eukaryotic and prokaryotic organisms 


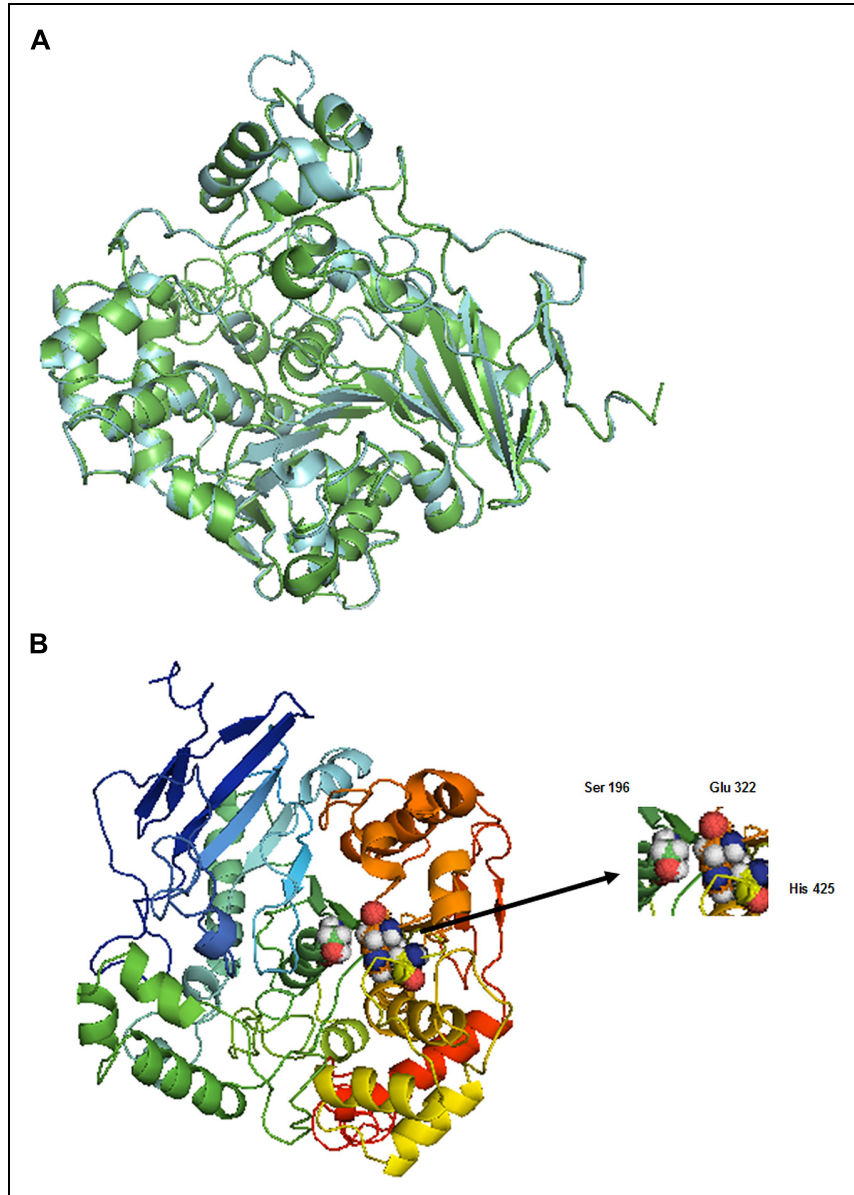

FIGURE 8 | Beauveria bassiana lipase A molecular modeling. (A) Superposition of structures from BbLA (blue) and EstA (green). The figure was made by I-TASSER (Zhang, 2008) using a TM-align structural alignment program. (B) 3D model of BbLA showing the catalytic triad (Ser, Glu, and His). The ribbon is colored with a rainbow spectrum from $\mathrm{N}$-terminus (blue) to C-terminus (red).

(Kobayashi et al., 2002; Maraite et al., 2013; Bouchaala et al., 2015).

Beauveria bassiana lipase A was immobilized on Duolite and C18-Sep. BbLA-derivatives were assayed in the fish oil ethanolysis to produce biodiesel. BbLA-C18 produced more fatty acid ethyl esters than BbLA-Duolite after $48 \mathrm{~h}$ reaction. Nevertheless, BbLADuolite was more selective for EPA-ester production than BbLAC18. For enzymatic biodiesel production, the final yield is the most relevant factor to be evaluated; however the selectivity can be used as the basis for development of enzymatic cocktails of lipases with different specificities, according to the type of oil used.

Lipases from different sources, even when immobilized on the same type of support, may present different selectivity. In a previous ethanolysis study [49], the authors obtained different degrees of selectivity (EPA/DHA) for CALB (3.0), TLL (29.0) and RML (13.0), immobilized on C18-Sep. Catalyst selectivity was influenced by the nature of the support used for immobilization, where TLL-C18 was more specific than TLL-Duolite and the
TABLE 3 | Beauveria bassiana lipase A kinetic parameters obtained using pNPB as substrate in $25 \mathrm{mM}$ phosphate buffer, $\mathrm{pH}$ 6.0, after incubation at $50^{\circ} \mathrm{C}$, for $2 \mathrm{~min}$.

\begin{tabular}{|c|c|c|c|c|}
\hline $\begin{array}{l}V_{\max } \\
\left(\mu \mathrm{mol} \cdot \mathrm{min}^{-1} \cdot \mathrm{mg}^{-1}\right)\end{array}$ & $\begin{array}{l}\mathrm{K}_{M} \\
(\mu \mathrm{M})\end{array}$ & $K_{\text {cat }}\left(s^{-1}\right)$ & $\begin{array}{l}K_{\text {cat }} / K_{M} \\
\left(M^{-1} 1 . s^{-1}\right)\end{array}$ & $n$ \\
\hline 85.67 & 0.5546 & $7.139 \times 10^{4}$ & $1.29 \times 10^{11}$ & 1.46 \\
\hline
\end{tabular}

GraphPad Prism 6.0 was used to calculate $V_{\max }, K_{M}$ and $n . n$, Hill coefficient.

TABLE 4 | Sardine oil Ethanolysis catalyzed by Duolite-BbLA and BbLA-C18 derivatives in the presence of cyclohexane.

\begin{tabular}{lccc}
\hline Derivative & Selectivity (EPA/DHA) & \multicolumn{2}{c}{ Ethanolysis (\%) } \\
\cline { 3 - 4 } & & EPA & DHA \\
\hline BbLA-Duolite $^{\mathrm{a}}$ & 5.57 & 0.66 & 0.18 \\
BbLA-C18 $^{\mathrm{b}}$ & 2.98 & 4.85 & 2.45 \\
\hline
\end{tabular}

The reaction occurred at $25^{\circ} \mathrm{C}, 100 \mathrm{rpm} .{ }^{\mathrm{a}} 48 \mathrm{~h}$ of reaction. ${ }^{\mathrm{b}} 24 \mathrm{~h}$ of reaction.

selectivity were 29 and 12, respectively (Moreno-Perez et al., 2014). It is noteworthy that the TLL also showed differences in selectivity when immobilized in the same supports used for BbLA.

Biodiesel production by BbLA-C18 may be improved through the study of several factors, such as increasing the amount of enzyme on the support, changing the organic solvent used, altering the temperature and the efficiency of transesterification on other oils. The present results demonstrate that the search for new enzyme sources together with the modulation of the activity by enzyme immobilization are valuable strategies for the development of biotechnological routes for biofuels production.

\section{Conclusion}

A B. bassiana Lipase A was expressed as a heterologous protein in $K$. pastoris, and the biochemical characteristics of the BbLA show potential for biodiesel production. The differential immobilization, by anionic and hydrophobic interaction, can generate products with different proportions of EPA and DHA esters, at mild temperatures, reducing the energy costs for biodiesel production.

\section{Author Contributions}

This work is part of the doctorate thesis of ACV and she is the main author. AC, RF-M, RW, and FT had collaboration in part of the experiments with molecular biology and fungal expression (enzyme assays optimum temperatures and heterologous protein expression). RW performed the circular dichroism. CC performed the molecular modeling BbLA and its analysis. BP, GF-L, FF and MGP had collaboration in the immobilization and application of enzyme. JJ designed some experiments; MLTMP contributed with the experimental design and the final manuscript. 


\section{Acknowledgments}

This work was supported by grants from Fundação de Amparo à Pesquisa do Estado de São Paulo - Consejo Superior de Investigaciones Cientificas (FAPESP-CSIC, process 2013/508925), Conselho de Desenvolvimento Científico e Tecnológico (CNPq), National System for Research on Biodiversity (SisbiotaBrazil, CNPq 563260/2010-6/FAPESP $n^{\circ}$ 2010/52322-3) and CNPq Biodiesel Process n ${ }^{\circ}$ 406838/2013-5. FAG Torres, JJ, MLTP and RJ Ward are Research Fellows of CNPq. FA Facchini was

\section{References}

Ali, S., Huang, Z., and Ren, S. X. (2009). Production and extraction of extracellular lipase from the entomopathogenic fungus Isaria fumosoroseus (Cordycipitaceae. Hypocreales). Biocontrol Sci. Technol. 19, 81-89. doi: $10.1080 / 09583150802588524$

Ali, S., Ren, S., and Huang, Z. (2014). Extracellular lipase of an entomopathogenic fungus effecting larvae of a scale insect. J. Basic Microbiol. 54, 1148-1145. doi: 10.1002/jobm.201300813

Bancerz, R., and Ginalska, G. (2007). A novel thermostable lipase from Basidiomycete Bjerkandera adusta R59: characterisation and esterification studies. J. Ind. Microbiol. Biotechnol. 34, 553-560. doi: 10.1007/s10295-0070232-6

Bancerz, R., Ginalska, G., Fiedurek, J., and Gromada, A. (2005). Cultivation conditions and properties of extracellular crude lipase from the psychrotrophic fungus Penicillium chrysogenum 9'. J. Ind. Microbiol. Biotechnol. 32, 253-260. doi: 10.1007/s10295-005-0235-0

Batista, A. C. F., Silva, T. A., Vieira, A. T., and Oliveira, M. F. (2013). "Biotechonological applications of lipases in biodiesel production," in Fungal Enzymes, eds M. L. T. M. Polizeli and M. Rai (New York: CRC Press), 294-315.

Bertolini, M. C., Schrag, J. D., Cygler, M., Ziomek, E., Thomas, D. Y., and Vernet, T. (1995). Expression and characterization of Geotrichum candidum lipase I gene. Eur. J. Biochem. 228, 863-869. doi: 10.1111/j.1432-1033.1995.0863m.x

Bisen, P., Sanodiya, B., Thakur, G., Baghel, R., and Prasad, G. B. K. S. (2010). Biodiesel production with special emphasis on lipase-catalyzed transesterification. Biotechnol. Lett. 32, 1019-1030. doi: 10.1007/s10529-0100275-z

Bouchaala, E., Bouali, M., Ali, Y. B., Miled, N., Gargouri, Y., and Fendri, A. (2015). Biochemical characterization and molecular modeling of pancreatic lipase from a cartilaginous fish, the common stingray (Dasyatis pastinaca). Appl. Biochem. Biotechnol. 176, 151-169. doi: 10.1007/s12010-015-1564-8

Bourne, Y., Hasper, A. A., Chahinian, H., Juin, M., De Graaff, L. H., and Marchot, P. (2004). Aspergillus niger protein EstA defines a new class of fungal esterases within the alpha/beta hydrolase fold superfamily of proteins. Structure 12, 677-687. doi: 10.1016/j.str.2004.03.005

Bradford, M. M. (1976). Rapid and sensitive method for quantitation of microgram quantities of protein utilizing principle of protein-dye binding. Anal. Biochem. 72, 248-254. doi: 10.1006/abio.1976.9999

Cavalcanti-Oliveira, E. A., Silva, P. R., Ramos, A. P., Aranda, D. A., and Freire, D. M. (2011). Study of soybean oil hydrolysis catalyzed by Thermomyces lanuginosus lipase and its application to biodiesel production via hydroesterification. Enzyme Res. 2011, 1-8. doi: 10.4061/2011/618692

Chahinian, H., and Sarda, L. (2009). Distinction between esterases and lipases: comparative biochemical properties of sequence-related carboxylesterases. Protein Peptide Lett. 16, 1149-1161. doi: 10.2174/092986609789071333

Deane, C. M., and Blundell, T. L. (2003). "Protein comparative modelling and drug discovery," in The Practice of Medicinal Chemistry, ed. C. G. Wermuth (London: Elsevier Academic Press), 445-458.

Edgar, R. C. (2004). MUSCLE: multiple sequence alignment with high accuracy and high throughput. Nucleic Acids Res. 32, 1792-1797. doi: 10.1093/Nar/Gkh340

Fang, Z. G., Xu, L., Pan, D. J., Jiao, L. C., Liu, Z. M., and Yan, Y. J. (2014). Enhanced production of Thermomyces lanuginosus lipase in Pichia pastoris via genetic and fermentation strategies. J. Ind. Microbiol. Biotechnol. 41, 1541-1551. doi: 10.1007/s10295-014-1491-7
FAPESP fellows; AV and MGP were CNPq fellows, AC and CC were CAPES fellows. The authors sincerely thank Mariana Cereia and Ricardo Alarcon for technical support.

\section{Supplementary Material}

The Supplementary Material for this article can be found online at: http://journal.frontiersin.org/article/10.3389/fmicb. 2015.01083

Fonseca-Maldonado, R., Vieira, D. S., Alponti, J. S., Bonneil, E., Thibault, P., and Ward, R. J. (2013). Engineering the pattern of protein glycosylation modulates the thermostability of a GH11 xylanase. J. Biol. Chem. 288, 25522-25534. doi: 10.1074/jbc.M113.485953

Freire, D. M. G., and Castilho, L. R. (2008). “Lipases em biocatálise”, in Enzimas em Biotecnologia: Produção, Aplicações e Mercado, eds E. P. S. Bon, M. A. Ferrara, M. L. Corvo, A. B. Vermelho, C. L. A. Paiva, R. B. Alencastro, et al. (Rio de Janeiro: Editora Interciência), 369-385.

Gotor, V. (2002). Lipases and (R)-oxynitrilases: useful tools in organic synthesis. J. Biotechnol. 96, 35-42. doi: 10.1016/S0168-1656(02)00035-4

Hasan, F., Shah, A. A., and Hameed, A. (2006). Industrial applications of microbial lipases. Enzyme Microb Technol. 39, 235-251. doi: 10.1016/j.enzmictec.2005.10.016

Hasan, F., Shah, A. A., and Hameed, A. (2009). Methods for detection and characterization of lipases: a comprehensive review. Biotechnol. Adv. 27, 782-798. doi: 10.1016/j.biotechadv.2009.06.001

Iso, M., Chen, B. X., Eguchi, M., Kudo, T., and Shrestha, S. (2001). Production of biodiesel fuel from triglycerides and alcohol using immobilized lipase. J. Mol. Catal. B Enzym 16, 53-58. doi: 10.1016/S1381-1177(01)00045-5

Jaeger, K. E., Dijkstra, B. W., and Reetz, M. T. (1999). Bacterial biocatalysts: molecular biology, three-dimensional structures, and biotechnological applications of lipases. Annu. Rev. Microbiol. 53, 315-351. doi: 10.1146/annurev.micro.53.1.315

Jaeger, K. E., Ransac, S., Dijkstra, B. W., Colson, C., Vanheuvel, M., and Misset, O. (1994). Bacterial lipases. FEMS Microbiol. Rev. 15, 29-63. doi: 10.1111/j.15746976.1994.tb00121.x

Jaeger, K. E., and Reetz, M. T. (1998). Microbial lipases form versatile tools for biotechnology. Trends Biotechnol. 16, 396-403. doi: 10.1016/S01677799(98)01195-0

Kempka, A. P., Lipke, N. L., Da Luz Fontoura Pinheiro, T., Menoncin, S., Treichel, H., Freire, D. M., et al. (2008). Response surface method to optimize the production and characterization of lipase from Penicillium verrucosum in solid-state fermentation. Bioprocess Biosyst. Eng. 31, 119-125. doi: 10.1007/s00449-007-0154-8

Khanna, P., Sundari, S. S., and Kumar, N. J. (1995). Production, isolation and partial purification of xylanases from an Aspergillus sp. World J. Microbiol. Biotechnol. 11, 242-243. doi: 10.1007/BF00704661

Kobayashi, Y., Nakajima, T., and Inoue, I. (2002). Molecular modeling of the dimeric structure of human lipoprotein lipase and functional studies of the carboxyl-terminal domain. Eur. J. Biochem. 269, 4701-4710. doi: 10.1046/j.1432-1033.2002.03179.x

Kohler, J., and Wunsch, B. (2007). The allosteric modulation of lipases and its possible biological relevance. Theor. Biol. Med. Model. 4, 34. doi: 10.1186/17424682-4-34

Krishna, S. H., and Karanth, N. G. (2001). Lipase-catalyzed synthesis of isoamyl butyrate - A kinetic study. Biochim. Biophys. Acta Protein Struct. Mol. Enzymol. 1547, 262-267. doi: 10.1016/S0167-4838(01)00194-7

Laemmli, U. K. (1970). Cleavage of structural proteins during assembly of head of Bacteriophage-T4. Nature 227, 680-685. doi: 10.1038/227 $680 \mathrm{a} 0$

Laskowski, R. A., Macarthur, M. W., Moss, D. S., and Thornton, J. M. (1993). Procheck - a program to check the stereochemical quality of protein structures. J. Appl. Crystallogr. 26, 283-291. doi: 10.1107/S00218898920 09944 
Lotti, M., and Alberghina, L. (2007). "Lipases: molecular structure and function," in Industrial Enzymes. Structure, Function and Applications, eds J. Polaina and A. P. Maccabe (Dordrecht: Springer), 263-300.

Madan, B., and Mishra, P. (2009). Overexpression, purification and characterization of organic solvent stable lipase from Bacillus licheniformis RSP-09. J. Mol. Microbiol. Biotechnol. 17, 118-123. doi: 10.1159/000208523

Maraite, A., Hoyos, P., Carballeira, J. D., Cabrera, Á. C., AnsorgeSchumacher, M. B., and Alcántara, A. R. (2013). Lipase from Pseudomonas stutzeri: purification, homology modelling and rational explanation of the substrate binding mode. J. Mol. Catal. B Enzym 87, 88-98. doi: 10.1016/j.molcatb.2012.11.005

Mateo, C., Palomo, J. M., Fernandez-Lorente, G., Guisan, J. M., and FernandezLafuente, R. (2007). Improvement of enzyme activity, stability and selectivity via immobilization techniques. Enzyme Microb. Technol. 40, 1451-1463. doi: 10.1016/j.enzmictec.2007.01.018

Matsumoto, T., Takahashi, S., Kaieda, M., Ueda, M., Tanaka, A., Fukuda, H., et al. (2001). Yeast whole-cell biocatalyst constructed by intracellular overproduction of Rhizopus oryzae lipase is applicable to biodiesel fuel production. Appl. Microbiol. Biotechnol. 57, 515-520. doi: 10.1007/s002530100733

Messaoudi, A., Belguith, H., and Ben Hamida, J. (2011). Three-dimensional structure of Arabidopsis thaliana lipase predicted by homology modeling method. Evol. Bioinform. Online 7, 99-105. doi: 10.4137/EBO.S7122

Mogensen, J. E., Sehgal, P., and Otzen, D. E. (2005). Activation, inhibition, and destabilization of Thermomyces lanuginosus lipase by detergents. Biochemistry 44, 1719-1730. doi: 10.1021/bi0479757

Moreno-Perez, S., Guisan, J. M., and Fernandez-Lorente, G. (2014). Selective ethanolysis of fish oil catalyzed by immobilized lipases. J. Am. Oil Chem. Soc. 91, 63-69. doi: 10.1007/s10529-011-0671-z

Mustafa, U., and Kaur, G. (2010). Studies on extracellular enzyme production in Beauveria bassiana isolates. Int. J. Biotechnol. Biochem. 6, 701-713.

Palomo, J. M., Fernandez-Lorente, G., Mateo, C., Ortiz, C., Fernandez-Lafuente, R., and Guisan, J. M. (2002). Modulation of the enantioselectivity of lipases via controlled immobilization and medium engineering: hydrolytic resolution of mandelic acid esters. Enzyme Microb Technol. 31, 775-783. doi: 10.1016/S01410229(02)00169-2

Palomo, J. M., Fernández-Lorente, G., Mateo, C., Segura, R. L., Ortiz, C., Fernandez-Lafuente, R., et al. (2006). "Purification, immobilization, hyperactivation, and stabilization of lipases by selective adsorption on hydrophobic supports," in Immobilization of Enzymes and Cells, ed. J. M. Guisan (New Jersey: Humana Press), 143-152.

Parawira, W. (2009). Biotechnological production of biodiesel fuel using biocatalysed transesterification: a review. Crit. Rev. Biotechnol. 29, 82-93. doi: 10.1080/07388550902823674

Salameh, M. A., and Wiegel, J. (2010). Effects of detergents on activity, thermostability and aggregation of two alkalithermophilic lipases from Thermosyntropha lipolytica. Open Biochem. J. 4, 22-28. doi: 10.2174/1874091X01004010022

Schrag, J. D., and Cygler, M. (1997). Lipases and alpha/beta hydrolase fold. Methods Enzymol. 284, 85-107. doi: 10.1016/S0076-6879(97)84006-2

Schrag, J. D., Li, Y. G., Wu, S., and Cygler, M. (1991). Ser-His-Glu triad forms the catalytic site of the lipase from Geotrichum candidum. Nature 351, 761-764. doi: $10.1038 / 351761 \mathrm{a} 0$
Silva, W. O. B., Mitidieri, S., Schrank, A., and Vainstein, M. H. (2005). Production and extraction of an extracellular lipase from the entomopathogenic fungus Metarhizium anisophae. Process Biochem. 40, 321-326. doi: 10.1016/j.procbio.2004.01.005

Singh, A. K., and Mukhopadhyay, M. (2012). Overview of fungal lipase: a review. Appl. Biochem. Biotechnol. 166, 486-520. doi: 10.1007/s12010-011-9444-3

Volpato, G., Filice, M., De Las Rivas, B., Rodrigues, R. C., Heck, J. X., FernandezLafuente, R., et al. (2011). Purification, immobilization, and characterization of a specific lipase from Staphylococcus warneri EX17 by enzyme fractionating via adsorption on different hydrophobic supports. Biotechnol. Prog. 27, 717-723. doi: 10.1002/btpr.601

Wang, D. L., Nag, A., Lee, G. C., and Shaw, J. F. (2002). Factors affecting the resolution of dl-menthol by immobilized lipase-catalyzed esterification in organic solvent. J. Agric. Food Chem. 50, 262-265. doi: 10.1021/ jf010657j

Wang, X., Sun, Y., Ke, F., Zhao, H., Liu, T., Xu, L., et al. (2012). Constitutive expression of Yarrowia lipolytica lipase LIP2 in Pichia pastoris using GAP as promoter. Appl. Biochem. Biotechnol. 166, 1355-1367. doi: 10.1007/s12010-0119524-4

Wang, Y. F., Lalonde, J. J., Momongan, M., Bergbreiter, D. E., and Wong, C. H. (1988). Lipase-catalyzed irreversible transesterifications using enol esters as acylating reagents - preparative enantioselective and regioselective syntheses of alcohols, glycerol derivatives, sugars, and organometallics. J. Am. Chem. Soc. 110, 7200-7205. doi: 10.1021/Ja00229a041

Wolski, E., Rigo, E., Di Luccio, M., Oliveira, J. V., De Oliveira, D., and Treichel, H. (2009). Production and partial characterization of lipases from a newly isolated Penicillium sp. using experimental design. Lett. Appl. Microbiol. 49, 60-66. doi: 10.1111/j.1472-765X.2009.02620.x

Xiao, G., Ying, S. H., Zheng, P., Wang, Z. L., Zhang, S., Xie, X. Q., et al. (2012). Genomic perspectives on the evolution of fungal entomopathogenicity in Beauveria bassiana. Sci. Rep. 2, 483. doi: 10.1038/srep00483

Yang, K. S., Sohn, J.-H., and Kim, H. K. (2009). Catalytic properties of a lipase from Photobacterium lipolyticum for biodiesel production containing a high methanol concentration. J. Biosci. Bioeng. 107, 599-604. doi: 10.1016/j.jbiosc.2009.01.009

Yu, X.-W., Wang, L.-L., and Xu, Y. (2009). Rhizopus chinensis lipase: gene cloning, expression in Pichia pastoris and properties. J. Mol. Catal. B Enzym 57, 304-311. doi: 10.1016/j.molcatb.2008.10.002

Zhang, Y. (2008). Progress and challenges in protein structure prediction. Curr. Opin. Struct. Biol. 18, 342-348. doi: 10.1016/i.sbi.2008.02.004

Conflict of Interest Statement: The authors declare that the research was conducted in the absence of any commercial or financial relationships that could be construed as a potential conflict of interest.

Copyright $(2015$ Vici, da Cruz, Facchini, de Carvalho, Pereira, Fonseca-Maldonado, Ward, Pessela, Fernandez-Lorente, Torres, Jorge and Polizeli. This is an open-access article distributed under the terms of the Creative Commons Attribution License (CC BY). The use, distribution or reproduction in other forums is permitted, provided the original author(s) or licensor are credited and that the original publication in this journal is cited, in accordance with accepted academic practice. No use, distribution or reproduction is permitted which does not comply with these terms. 